\title{
LOS SILENCIOS Y LAS PALABRAS: EL TESTIMONIO COMO POSIBILIDAD
}

\author{
SILENCES AND WORDS: TESTIMONY AS POSSIBILITY
}

\section{MARÍA OLGA RUIZ*}

\section{RESUMEN}

En el presente artículo se analizan los límites y posibilidades del testimonio como herramienta para comprender el pasado reciente y, en particular, la experiencia del terrorismo de Estado. Para ello se analizan temáticas que cruzan la narrativa testimonial, a saber: la vergüenza, la culpa y el silencio. En el marco del boom de la memoria y el giro testimonial, se analizan las disputas académico-políticas en torno a la noción de verdad histórica y su relación con la memoria.

Palabras clave: Testimonio, silencio, terrorismo de Estado, verdad, memoria.

\section{ABSTRACT}

In the following article the limits and possibilities of testimony as a way for understanding recent events is analyzed, and, particularly, the experience of State Terrorism. Themes are studied that traverse distinct testimonial narratives: shame, guilt and silence. In the framework of the boom of memory and the testimonial turn, political-academic disputes around the notion of historical truth and its relation to memory are analyzed.

Key words: Testimony, silence, state terrorism, truth, memory.

Recibido: 07.11.13. Aceptado: 26.03.14.

* Licenciada en Historia. Magíster en Estudios Latinoamericanos. Magíster en Estudios de Género y Cultura en América Latina, Universidad de Chile. Candidata a Doctora en Estudios Latinoamericanos, Universidad de Chile. Instituto de Estudios Indígenas e Interculturales, Universidad de la Frontera. Temuco, Chile. E-mail: olgaruizc@gmail.com 

PARTIR DE LA DÉCADA del sesenta la producción testimonial adquirió una presencia significativa en América Latina. Progresivamente, el testimonio fue ganando espacio y legitimidad en tanto discurso de resistencia que posibilitaba a los sectores subalternos hablar por sí mismos. En la actualidad, lo que algunos han identificado como fiebre testimonial es expresión de un proceso más amplio que se despliega en las sociedades occidentales como una obsesión por el pasado: la topolotría-expresada en el rescate y la marcación de lugares-, la arremetida comercial del marketing de la nostalgia y la configuración de un campo académico especializado, son expresiones del denominado boom memoralístico (Huyssen, 2002; Traverso, 2007).

Desde la instalación de las dictaduras cívico-militares, los testimonios fueron una herramienta fundamental para superar la negación institucional de los crímenes del Terrorismo de Estado y su carácter sistemático. Sin embargo, sus alcances superaron la mera denuncia, instalándose como un reto a las estructuras tradicionales no solo del poder político sino también de la academia y sus marcos disciplinarios. Señala Emma Sepúlveda: "El testimonio por definición, abre un espacio para el reconocimiento público y personal de la voz antes marginada, de lo reprimido social y políticamente, de aquellos cuyo silencio se exige por el privilegio tradicional del discurso y de la 'historia oficial'" (Sepúlveda, 1995:19). Definido como una narración de urgencia (Jara y Vidal, 1986), en tanto surge en el marco de condiciones irregulares (represión, pobreza, marginalidad) que el sujeto desea comunicar, el testimonio logró un sitial de relevancia significativa en 1970, cuando 
Casa de las Américas estableció un premio específico a la narrativa testimonial. Años más tarde, en 1992, la asignación del Premio Nobel de la Paz a Rigoberta Menchú demostraría su potencial social y político.

Entre las múltiples razones que explican la proliferación testimonial, encontramos la relevancia alcanzada en la cultura latinoamericana por una serie de textos poco clasificables de acuerdo a las normas literarias canónicas. Asimismo, la popularidad adquirida por la historiografía etnográfica en las Ciencias Sociales (expresada en el uso recurrente de las historias de vida), la difusión masiva del testimonio guerrillero (en el marco de la Revolución Cubana y su impacto a nivel regional) y por último, el reconocimiento de su potencial emancipador en el contexto de la contracultura de los sesenta (cuya máxima 'lo personal es político' coincidía con los relatos en primera persona que -con un efecto metonímico- intentaban representar una situación problemática colectiva) son parte de un contexto que favoreció la difusión de este tipo de narrativa (Beverley, 1992).

En las últimas décadas se ha desarrollado una intensa producción crítica acerca de la narrativa testimonial. Ello se produce en un ambiente intelectual interesado en conocer la voz del otro, en el entendido de que a esas voces había que hacerles un lugar, un espacio para que se manifestaran y expresaran. De esta forma, el rol de los intelectuales era operativizar esa voluntad de escucha, dando a conocer la voz de esos sujetos. Esto ocurre en el contexto de una crisis de la representación, tanto intelectual como política que sostiene que las masas pueden prescindir de los intelectuales, pues ellas saben perfectamente lo que necesitan. De hecho, uno de los aspectos más problemáticos en la discusión acerca de este tipo de narrativa se refiere a la mediación realizada -habitualmente- por un profesional, el que graba, transcribe y/o redacta lo narrado por el sujeto subalterno, el que en muchas ocasiones requiere de un interlocutor de otra clase o formación cultural para dar forma textual a su narración. Desde esta perspectiva, uno de los objetivos del mediador es mostrar al mundo, hacer visible aquello invisibilizado por el poder.

El uso de testimonios para la investigación histórica de diversos sectores marginados o subalternos es ampliamente difundido. Es el caso de la historia de las mujeres, campo académico en el que no pocas investigadoras han destacado la relevancia de las fuentes orales en la reconstrucción historiográfica de la mitad invisible de la historia. Ello, no solo porque las mujeres habrían sido excluidas de la cultura letrada y tendrían, por lo mismo, una histórica cercanía con la oralidad; también porque el uso de estas metodologías supondría una inversión política y académica del orden dominante, 
al promover la construcción de conocimiento basada en una alianza entre mujeres (investigadoras e investigadas) sin intermediarios masculinos.

Así como en Europa el mayo francés de 1968 animó a ciertos intelectuales (Foucault, 1998) a afirmar la necesidad teórica y política de que los sujetos hablaran por sí mismos, en América Latina el testimonio es apreciado como estrategia de resistencia que debe estar alerta ante los intentos de domesticación académica y/o política. “...El testimonio surge precisamente en el contexto de una crisis de representatividad de los viejos partidos políticos, incluidos los de la izquierda. (...) Concretamente, tenemos la impresión que, tanto en las revoluciones centroamericanas como en los movimientos civiles en pro de los derechos humanos y la redemocratización en el Cono Sur, el testimonio ha sido no solo una representación de formas de resistencia y lucha sino también un medio y hasta un modelo para éstas" (Beverley, 1992: 16).

El giro subjetivo -que ha logrado instalarse exitosamente tanto en la academia como en el mercado- se propone reconstruir el pasado en base al rescate de la experiencia y la revaloración de la primera persona como punto de vista. Los sujetos terminaron por desplazar a las estructuras, en tanto perspectiva privilegiada para analizar la realidad social. Con ello, el testimonio se ha convertido no sólo en el recurso más demandado en los intentos por reconstruir la historia, sino que incluso opera como un ícono de verdad que ofrece certezas acerca de lo sucedido, lo que no va acompañado necesariamente de miradas que estimulen el debate y/o la reflexión crítica acerca de lo pasado reciente.

La crítica argentina Beatriz Sarlo (2005) parte de la base del reconocimiento del testimonio como instrumento jurídico indispensable para la condena y posterior juzgamiento de los militares y como forma de reconstrucción histórica, en especial cuando otro tipo de fuentes y documentos han sido destruidos por los responsables de los crímenes. Sus críticas al boom testimonial apuntan a su "... autorrepresentación como verdad de un sujeto que relata su experiencia, pide no someterse a las reglas que se aplican a otros discursos de intención referencial, alegando la verdad de la experiencia, cuando no la del sufrimiento, que es la que precisamente necesita ser examinada" (Sarlo, 2005: 47). El problema radica en asignar al testimonio un estatuto irrefutable, basado tanto en la inmediatez de la experiencia como en su incuestionable dimensión moral. Ello derivaría en una fetichización de la verdad testimonial, afirmada, a su vez, en la subvaloración de otros documentos. En este sentido, el deber de memoria establece una relación moral con el pasado, que puede no coincidir con la búsqueda 
de inteligibilidad de la labor historiográfica. Ciertamente, más allá de que la memoria pueda constituirse efectivamente en fuente e impulso moral de la historia, ello no es suficiente para respaldar sus pretensiones de verdad irrebatible.

El valor asignado a la narración subjetivada -por sobre la descripción fáctica de los hechos y procesos sobre los que se testimonia- reconoce que el principal mérito del testimonio radica en la transmisión de las formas en que los sujetos recuerdan, reelaboran y reconstruyen narrativamente su experiencia. Este giro testimonial admite y estimula la proliferación de verdades subjetivas (ante la imposibilidad de sostener una verdad), y la capacidad (¿espontánea?) de los sujetos para comunicar sus experiencias y asignarles sentido. En este punto no podemos sino remitirnos a las dudas planteadas por Gayatri Spivak en su ensayo de 1988 “ ¿Puede hablar el subalterno?", respecto a la capacidad que tienen los oprimidos para hablar (y el olvido u omisión de los posestructuralistas respecto a la mediación de la ideología en dicho proceso) cuestionando que los sujetos tengan, como condición previa, una plena posesión de sus conciencias que les permita hacer coincidir sus deseos con sus intereses.

\section{PENSAR LOS SILENCIOS}

Todo testimonio, más allá de la diversidad de sus registros (narración autobiográfica, declaración judicial, entrevista u otros registros), requiere de una escucha, de un otro (u otros) que acoja(n) las palabras del testimoniante. Sucede, sin embargo, que no siempre existen contextos favorables a la recepción de sus relatos. Primo Levi (2006) señala una pesadilla recurrente de los prisioneros de los campos nazis: luego de la liberación y estando en sus casas en medio de sus amigos y familiares, intentan contar los sufrimientos pasados, sin embargo, sus seres queridos dan vuelta el rostro y se alejan en silencio, sin deseos ni voluntad de escuchar ni creer sus historias. De este modo, la ausencia de un oyente provoca un vacío dialógico y/o la privatización del trauma (Jelin, 2006).

Así como se pone atención a las palabras, es necesario atender a los silencios que constituyen -tanto como las primeras- todo testimonio. El silencio tiene funciones y, por lo mismo, debe ser trabajado y no resuelto como si se tratara de un problema, puesto que la posibilidad de testimoniar no solo depende de la voluntad o capacidad de los sobrevivientes de narrar sus experiencias, sino de la existencia de condiciones sociales que las vuelvan 
comunicables y audibles. La frontera entre lo decible y lo indecible, entre aquello que el sujeto se confiesa a sí mismo y aquello que puede transmitir al exterior no es estática, y los recuerdos deben esperar el momento indicado para ser expresados. De hecho, ante la imposibilidad de hacerse oír y comprender, el silencio sobre sí mismo puede incluso ser una condición necesaria para mantener el vínculo con el entorno social.

El silencio puede operar como mecanismo de disciplinamiento y control político: mientras en periodos de autoritarismo la denuncia de ciertos hechos puede tener costos altísimos y, por lo mismo, el miedo obliga a las personas a callar como estrategia de sobrevivencia, en escenarios posdictatoriales, las palabras y los recuerdos aparecen como presencia molesta y amenazante para los pactos políticos y, por lo mismo, no hay espacio de recepción ni voluntad para escuchar o entender los relatos de las víctimas. Existen otros silencios que responden al deseo de no transmitir los sufrimientos; de ahí que muchos sobrevivientes guarden un secreto, aun en sus círculos afectivos más íntimos, secreto que puede tardar años en develarse.

\section{LA CULPA Y LA VERGÜENZA: SOBREVIVIR PARA TESTIMONIAR}

Por mucho tiempo se consideró que las principales -si no las únicas- víctimas de la represión política de la dictadura cívico-militar eran los asesinados y los desaparecidos. El valor asignado a la sobrevivencia condujo, en no pocas ocasiones, a subestimar las condiciones en que ésta se realizaba, desatendiendo los profundos daños que marcaron la vida de quienes sobrevivieron a la represión política. Desde esta perspectiva, los sobrevivientes debían sentir incluso una suerte de agradecimiento por continuar vivos, cuestión que los invitó a inhibir el relato de sus experiencias, siempre menores en relación con la muerte o el desaparecimiento.

La culpa asociada a la sobrevida ha sido abordada no solo por quienes han testimoniado y/o analizado la experiencia de los campos de concentración nazis (Primo Levi, Giorgio Agamben, Jorge Semprún), sino también por los sobrevivientes de las cárceles y centros clandestinos de las dictaduras del Cono Sur latinoamericano (Montealegre, Ramus, entre otros). Frecuentemente se buscan las razones que expliquen el destino de unos y otros. No siempre las hay, y cuando existen, nunca resultan suficientes. Tal como señala Susana Ramús (2000), sobreviviente de la Escuela de Mecánica de la Armada de Argentina: 
... No es mi culpa haber sobrevivido, es terriblemente doloroso serlo pero tengo que cargar con eso y seguir adelante (...) Sé que hay mucha gente que no piensa lo mismo, gente que nos juzga sin saber muy bien por qué, es como cuando decían que por algo será que nos detenían o nos secuestraban, como tender un manto de duda sobre nuestra conducta, como si haber sobrevivido fuera una traición y como si se sobreentendiera que se trató de haber colaborado (Ramus, 2000:37).

Los ex detenidos deben sobrevivir no sólo al secuestro, la tortura, la prisión y el exilio, sino también a la culpa de esa sobrevida. De acuerdo al análisis de la crítica argentina Ana Longoni (2007), los sobrevivientes son evaluados a partir de los modelos de heroísmo y valentía de quienes no regresaron y el desconcierto que provoca su presencia responde no sólo a que lo que narran es intolerable, sino a que sus relatos no contribuyen -necesariamente- a conservar una imagen incólume sobre el muerto o desaparecido. Asimismo, cuestionar o revisar críticamente las políticas revolucionarias implementadas en los años setenta puede ser considerada una traición a los mártires, una negación de su entrega y del valor de su sacrificio. Lo inaudible no solo sería el horror sino los balances políticos y personales que los reaparecidos pueden realizar acerca de su historia militante. De este modo, existiría una suerte de deber de memoria basado en el recuerdo acrítico de la experiencia de quienes no regresaron, deber cuyo cumplimiento impediría revisar desde nuevos puntos de vista y formular nuevas preguntas a una parte importante, compleja y dolorosa de nuestra historia reciente.

Tan presente como la culpa $-\mathrm{y}$ estrechamente vinculada a ella-, la vergüenza es otra de las emociones que predominan en los relatos de sobrevivientes. Primo Levi señala que al momento de abandonar los campos de concentración, los prisioneros que habían conseguido sobrevivir sentían vergüenza, pues la liberación les permitía recobrar la conciencia, la penosa lucidez, de haber sido envilecidos y denigrados:

Así, la hora de la libertad sonó para nosotros grave y difícil, y nos llenó el ánimo a la vez de gozo y de un doloroso sentimiento de pudor que nos movía a querer lavar nuestras conciencias y nuestras memorias de la suciedad que había en ellas: y de pena, porque sentíamos que aquello no podía suceder; que nunca ya podría suceder nada tan bueno y tan puro como para borrar nuestro pasado, y que las señales de las ofensas se quedarían en nosotros para siempre, en los recuerdos de quienes las vivieron, y en los lugares donde sucedieron, y en los relatos que haríamos de ellas (Levi, 1987: 12). 
La vergüenza se funda en la imposibilidad de nuestro ser de despegarse, de romper, de desolidarizar consigo mismo. El yo, aún reducido a la pasividad total, desubjetivado, anulado es, al mismo tiempo, presencia extrema e irreductible. La conciencia desmoronada, asiste sin embargo, a su propia ruina. "En la vergüenza el sujeto no tiene, en consecuencia, otro contenido que la propia desubjetivación, se convierte en testigo del propio perderse como sujeto. Este doble movimiento, a la vez de subjetivación y de desubjetivación, es la vergüenza" (Agamben, 2000: 110). Jorge Montealegre, poeta chileno que al momento de ser detenido tenía 19 años, señala:

Las cicatrices más profundas son invisibles (...) Una de esas cicatrices indelebles es la vergüenza. La vergüenza callada de quien sintió su dignidad perdida porque rogó patéticamente o negó sus creencias y a sus amigos. O porque no supo negar y todavía se arrepiente. La humillación tatuada de quien pidió perdón por ser lo que era, del que se sintió ridículo, del que sufrió por tener que desnudarse ante desconocidos, de quien asumió culpas inexistentes. (...) La vergüenza de quien sintió vergüenza. Del que lloró bajo la frazada. Del que sigue llorando en silencio cuando recuerda. Y duele. Y pesa. Como una manta mojada sobre la espalda (Montealegre, 2003: 146).

Asimismo, desde una mirada psicoanalítica, Silvia Amati ha señalado que en pacientes que han sufrido condiciones extremas como la tortura, los sentimientos de vergüenza son expresión de un deseo de incorruptibilidad y de la necesidad de recomponer la coherencia (Amati, 2006: 119).

La experiencia de testimoniar puede estar cruzada por una suerte de imperativo ético: hablar por los ausentes. Este deber de memoria no se refiere al relato monolítico que pretende ser transmitido como un cuerpo cerrado y sin posibilidades de resignificación en el marco de una política pública de memoria (Vinyes, 2009), sino al mandato que recae sobre muchos sobrevivientes que asumen la labor del testimonio como un deber, puesto que los hundidos -aquella inmensa mayoría que llegó hasta el fondo, sin posibilidades de retorno- no pueden hacerlo por sí mismos. Se testimonia por delegación, y para explicar la audacia de haber sobrevivido:

La necesidad de hablar a 'los demás', de hacer que 'los demás' supiesen, había asumido entre nosotros, antes de nuestra liberación y después de ella, el carácter de un impulso inmediato y violento, hasta el punto de que rivalizaba con nuestras demás necesidades más elementales (Levi, 1987: 10). 


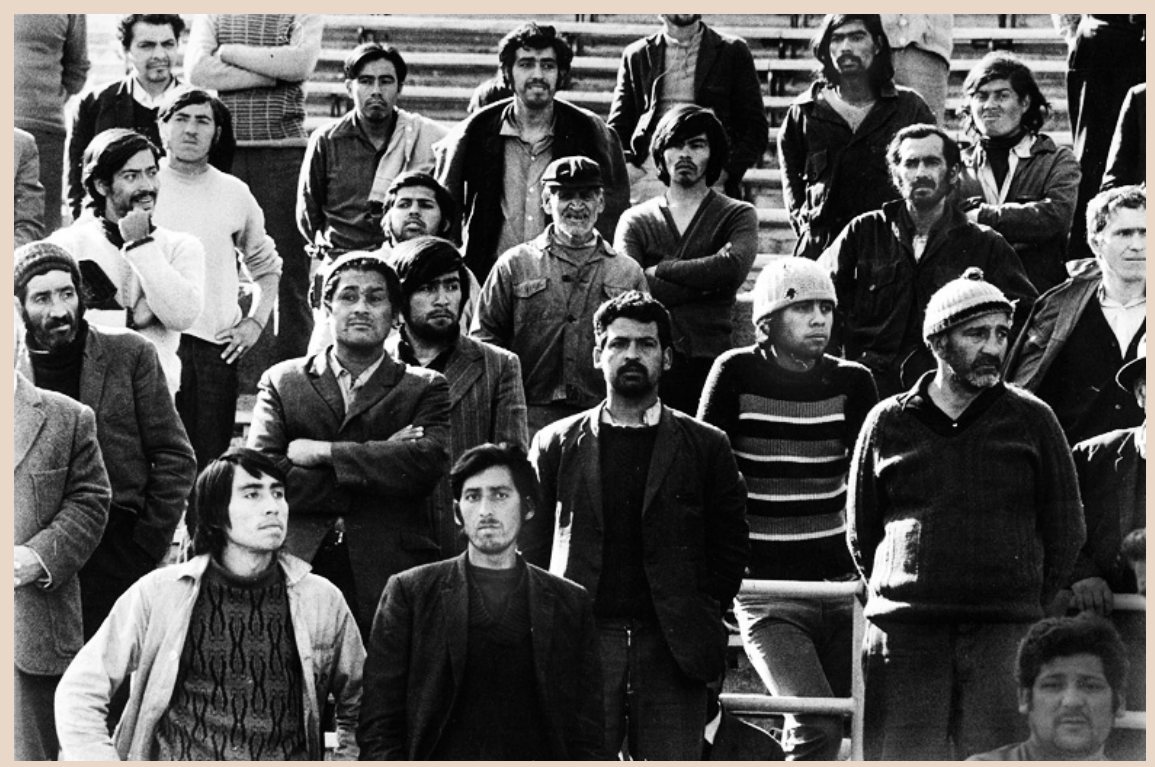

Prisioneros Estadio Nacional, Santiago, 1973.

El imperativo de incorporar los recuerdos particulares a memorias más amplias supone una paradoja para las víctimas. Jorge Montealegre señala que cumplir con la tarea de testimoniar implica mantener viva la experiencia de la represión; el recuerdo y el relato de los hechos puede suponer una reedición de los mismos, es decir, 'volver a pasar por el corazón' las humillaciones, el dolor, las violaciones a la intimidad.

... sus compañeros le pidieron que contara lo que les había ocurrido. Y él se comprometió, sin saber que cumplir con la tarea y llegar a este momento implicaba vivir una paradoja: mantener la dictadura 'aquí adentro'. (...) La memoria duele. Demora la escritura, con sus recuerdos de recuerdos. Es regresar. Y me pregunto si vale la pena, zigzagueando entre el escepticismo y la esperanza (Montealegre, 2003: 14, 15).

Asimismo, la construcción de una memoria pública sobre los crímenes del terrorismo de Estado requiere que las personas expongan -a veces públicamente- situaciones en que fueron violentados no solo sus derechos políticos sino también su privacidad. El imperativo de la verdad y la justicia requiere que declaren y testimonien una y otra vez, por sí mismos y por los otros, no solo ante tribunales de justicia, sino también ante iniciativas 
provenientes del mundo de los derechos humanos y la investigación académica. No pocos sobrevivientes, movilizados por el deber de memoria hacia sus compañeros y amigos muertos o desaparecidos, repasan una y otra vez la experiencia traumática y el registro de ese dolor circula -a veces incesantemente- por distintos canales y escenarios sociales. Los testimonios dan cuenta de situaciones límite que son, al mismo tiempo, íntimas y políticas, privadas y públicas, experiencias que además, si bien se inscriben temporalmente en el pasado - por haber ocurrido hace casi cuatro décadas-, son parte del presente de las personas y que no pocas veces se reactualizan (no pocas veces, involuntariamente). ¿Cómo recomponer la intimidad si el deber de memoria exige hacer públicas las heridas? ¿Puede el deber de memoria volverse en contra de las propias víctimas al demandar que recuerden una y otra vez la violencia, el dolor, las humillaciones? ¿Hay voluntad para acoger, ya no tan solo las palabras, sino también los silencios de los sobrevivientes?

Jorge Semprún advierte que ante el abatimiento emocional que provoca recordar, el silencio y el olvido permiten seguir viviendo. Liberado del campo de Buchenwald a los veintidós años, señala en su libro La escritura o la vida:

La vida tenía ese precio. Olvido deliberado, sistemático de la experiencia del campo. Olvido de la escritura igualmente (...). Tenía que escoger entre la escritura y la vida, había escogido ésta. Había escogido una prolongada cura de afasia, de amnesia deliberada para sobrevivir (Semprún, 2004: 212).

\section{LA VERDAD BAJO SOSPECHA}

... Sin la distinción entre lo que es y lo que no es, así no
puede haber historia. Roma venció y destruyó Carta-
go en las guerras púnicas y no viceversa. Cómo reu-
nimos e interpretamos nuestra muestra escogida de
datos verificables (que pueden incluir no solo lo que
pasó, sino lo que la gente pensó de ello) es otra cosa.

Hobsbawm (2002)

Al ser consultado por las causas del exterminio nazi, Claude Lanzmann señaló: "No entender fue mi ley de hierro durante los once años de producción de Shoa. Me aferré a este rechazo a entender como la única actitud ética posible y al mismo tiempo como la única actitud operativa. Esta ceguera fue para mí la condición vital para la creación. La ceguera debe ser comprendida aquí como el modo más puro de la mirada, la única manera 
de no alejarme de la realidad que era literalmente enceguecedora..." (Caruth, 1995). Declararnos ciegos ante la catástrofe, situar a la Shoa más allá de lo humanamente comprensible, afirmar la ininteligibilidad del horror, inscribir la catástrofe fuera de la historia, asignar a los crímenes un estatuto satánico o sobrenatural, esta posición ha sido refutada por quienes defienden no tan solo la capacidad sino también la necesidad de conocer, comprender -aunque sea parcialmente- $y$ transmitir el pasado.

Para ello es necesario relevar el componente intelectual de la memoria, que, impulsada por una voluntad de conocimiento, busca el entendimiento de los hechos (y no solo su denuncia) y procesos de autoentendimiento ético-políticos. Ello responde a la necesidad de producir un conocimiento histórico sobre ese pasado-presente, en tanto producción regulada y comunicable (transferible), lo cual supone reposicionar la noción de verdad histórica, es decir, el reconocimiento de hechos efectivamente sucedidos a partir de los cuales se elaboran memorias múltiples y hasta contradictorias.

El boom de la memoria y la proliferación testimonial que le acompaña nos obliga a revisar la relación entre memoria e historia, advirtiendo los aportes y límites del testimonio en la elaboración del conocimiento histórico. Pese a que entre quienes perciben el testimonio como estrategia de resistencia política e ideológica de los sectores subalternos suelen afirmar que la distinción entre lo verdadero y lo ficcional no es un aspecto relevante, lo cierto es que estas narraciones poseen una pretensión de verdad que se sostiene en una suerte de confianza depositada en la transparencia de los recuerdos de los sujetos.

Paul Ricœur (2002) sostiene que la paradoja de la memoria se basa en que el recuerdo se afirma en una presencia/ausencia, cuestión a la que hay que agregar la existencia de dos tipos de ausencia: la de lo irreal (lo imaginario, lo fantástico) y la de lo anterior (ausencia de lo pasado, de lo que existió antes). En relación a ello, se manifiesta en contra de la tendencia que empuja a la memoria hacia lo irreal y el terreno de lo imaginario, defendiendo la necesidad y el imperativo de ser fiel al pasado, es decir, de intentar fortalecer la relación de la memoria con lo pasado, con la historia.

En las últimas décadas no pocos historiadores europeos han revalorizado el principio de realidad que funda la historia, ello como respuesta a aquellas voces que -incluso desde la academia- negaban la existencia de las cámaras de gas. Frente a la necesidad de establecer la verdad sobre los crímenes del totalitarismo, Habermas (1998) discute con los historiadores revisionistas acerca de la experiencia del nazismo, planteando la necesidad de construir un consenso -y por ende, de poner un límite al pluralismo- 
en la interpretación de acontecimientos decisivos del pasado. En América Latina en tanto, el término memoria apareció para afirmar la resistencia de los recuerdos a las tentativas oficiales de negar lo sucedido. Parecer ser que, asumiendo la existencia de memorias diversas e incluso antagónicas en una sociedad heterogénea, es necesario que exista una voluntad explícita de mantener un espacio de debate en el cual la dimensión de una verdad histórica -por muy provisional que sea- esté permanentemente en juego.

Ahora bien, la defensa de la noción de verdad histórica ha sido y sigue siendo duramente cuestionada. La desconfianza -o abierto rechazo- respecto a la existencia de una verdad histórica descansa en el reconocimiento de las múltiples perspectivas desde donde se puede observar la realidad, de modo que "(...) la ilusión referencial de un saber soberano, la confiada certeza que observaba en el oficio historiográfico lo que realmente es la verdad, la verdad desnuda, ha cedido su lugar al juego de citas de la biblioteca de Babel. El vértigo de la posición, la multiplicación infinita de los puntos de mirada y la propia autoconciencia de la relatividad de toda perspectiva histórica, han terminado por imponer una crisis en el sentido mismo de la historicidad" (Valderrama, 2004). Estos planteamientos no apuntan únicamente a desestabilizar las pretensiones de neutralidad, imparcialidad y objetividad científica del quehacer historiográfico, develando con ello la implicancia del historiador en el mundo (argumento que difícilmente alguien podría refutar), sino que ponen en duda la posibilidad de distinguir entre lo verdadero y lo falso, la realidad de la ficción. Desde esta perspectiva, toda historia debe asumirse como una versión más, entre muchas otras igualmente válidas y legítimas. Esta posición dialoga productivamente con aquellas propuestas que afirman que la historiografía no es más que un tipo específico de narración literaria y que los datos escogidos por el historiador serían el resultado de un protocolo lingüístico y de un particular entramado argumentativo. De este modo, el valor del trabajo historiográfico no radicaría en su veracidad referencial y, por el contrario, la ficcionalización de la historia permitiría dar paso a nuevas formas de interpretación y representación del pasado.

Desde nuestra perspectiva, la aceptación de que no existe una historia neutra o aséptica, y el reconocimiento de la intervención del historiador en la reconstrucción del pasado no tiene por qué derivar en la homologación o identificación absoluta entre memoria e historia, pues si bien ambas intentan representar lo ausente, la historia posee sus propios mecanismos de legitimación y espacios de circulación. Asimismo, se hace necesario reivin- 
dicar la posibilidad de conocer el pasado y de aproximarse al conocimiento histórico, por elusivo que éste resulte, advirtiendo junto a Roger Chartier, que si bien la historia es una representación de los hechos pasados -y no su restitución-, ésta tiene un carácter diferente al de la ficción literaria ya que intenta preservar una forma de conocimiento del pasado verificable y transmisible. A partir de la constatación de que toda historia es siempre un relato organizado que pone en juego una serie de elementos narrativos, el historiador cuestiona la afirmación de Hayden White (2003) respecto a que la labor historiográfica no es más que una 'fiction making operation'. Frente al desdibujamiento de los límites entre ficción e historia, Chartier nos advierte sobre los riesgos de falsificación histórica, pues “(...) Abandonar esta intención de verdad, que fundamenta la historia como disciplina crítica, sería dejar el campo libre a todas las falsificaciones, a todos los falsarios que, porque traicionan al conocimiento, hieren la memoria. Los historiadores, al hacer su tarea, deben estar alertas y vigilantes" (Chartier, 1996: 33).

Parece ser evidente que la labor historiográfica puede enriquecerse al considerar las voces de los sobrevivientes, puesto que las narrativas personales acerca de la experiencia dictatorial están constituidas tanto por hechos históricos como por el impacto de esos acontecimientos en la vida de los sujetos. Por lo mismo, separar las experiencias de los significados que tuvieron para las personas, implica subestimar una parte de la realidad histórica. El análisis histórico sobre el terrorismo de Estado y nuestra historia reciente debiera tener en consideración no sólo los hechos sino también su representación y el modo en que son recordados. Sin embargo, este reconocimiento debe ir acompañado de una necesaria $-y$ desde nuestro punto de vista, provechosa- distinción entre memoria e historia, y, al mismo tiempo, estar inspirado por la voluntad de indagar y analizar el pasado, para lo cual es importante rescatar el vínculo entre rememoración e intelección.

La producción testimonial, aunque indispensable, es insuficiente si no va acompañada de una práctica intelectual crítica que promueva y estimule la posibilidad de comprender las condiciones que permitieron lo ocurrido y sus repercusiones políticas y culturales en el presente. En otras palabras, hay que analizar la experiencia y no solo rememorarla (un buen ejemplo de ello es la obra de Primo Levi), más aún considerando los peligros que reviste la trivialización mediática sobre la memoria, la que poniendo énfasis en los dramas e historias personales, puede derivar en la saturación y la banalización del horror. 


\section{REFERENCIAS}

Agamben, G. (2000). Lo que queda de Auschwitz. Valencia: Editorial Pre-textos. Amati, S. (2006). "Recuperar la vergüenza”. En: Kaes, R. y Puget, J., Violencia de Estado y psicoanálisis. Buenos Aires: Editorial Lumen.

Beverley, J. (1992). “Anatomía del testimonio". En: Revista de Crítica Literaria Latinoamericana 36.

Caruth, C. (ed.) (1995). Trauma. Explorations in Memory. Baltimore/Londres: Johns Hopkins University.

Chartier, R. (1996a). El mundo como representación. Historia cultural: entre práctica y representación, Editorial Gedisa, Barcelona.

(1996b). "La historia hoy en día: dudas, desafíos, propuestas". En: Olábarri, I. y Caspistegui, F. J. (eds.), La nueva historia cultural: la influencia del postestructuralismo y el auge de la interdisciplinariedad. Madrid: Editorial Complutense.

Foucault, M. (1998). Un diálogo sobre el poder y otras conversaciones. Madrid: Alianza Editorial.

Habermas, J. (1998). "Un doble pasado: ¿Qué significa hacer frente al pasado aclarándolo?”. En Habermas, J., Más allá del Estado Nacional. México D.F.: Fondo de Cultura Económica.

Hobsbawm, E. (2002). Sobre la historia. Barcelona: Editorial Crítica.

Huyssen, A. (2002). En busca del futuro perdido: cultura y memoria en tiempos de globalización. México D.F.: Fondo de Cultura Económica.

Jara, R. y Vidal, H. (eds.) (1986). Testimonio y literatura. Minneapolis: Institute for the Study of Ideologies and Literature.

Jelin, E. (2006). "La narrativa personal de lo 'invivible"'. En: Vera Carnovale et al., Historia, memoria y fuentes orales. Buenos Aires: Memoria Abierta y CEDINCI editores.

Levi, P. (1987). Si esto es un hombre. Barcelona: Editorial Muchnik.

(2005). "Il supérstite". De: Ad ora incerta. Italia: Garzanti Libri. Traducción de Jorge Montealegre.

(2006). Trilogía de Auschwitz. Barcelona: El Aleph Editores.

Longoni, A. (2007). Traiciones. La figura del traidor en los relatos acerca de los sobrevivientes de la represión. Buenos Aires: Grupo Editorial Norma.

Montealegre, J. (2003). Frazadas del Estadio Nacional. Santiago de Chile: Lom Ediciones.

Ramus, S. (2000). Sueños sobrevivientes de una montonera. Buenos Aires: Editorial Colihue.

Ricœur, P. (2002). "Definición de la memoria desde un punto de vista filosófico". En: VV.AA., ¿Por qué recordar? Barcelona: Editorial Granica.

Sarlo, B. (2005). Tiempo pasado. Cultura de la memoria y giro subjetivo. Una discusión. Buenos Aires: Siglo XXI Editores.

Semprún, J. (2004). La escritura o la vida. Barcelona: Tusquets. 
Sepúlveda, E. (1995). El testimonio femenino como escritura contestataria. Santiago: Asterion.

Spivak, G. (1988). “¿Puede hablar el subalterno?”. Orbis Tertius, año III, No 6.

Traverso, E. (2007). El pasado, instrucciones de uso. Historia, memoria, política. Madrid: Editorial Marcial Pons.

Valderrama, M. (2004). "Historia y verdad, una vez más”. En: Fronteras de la Emancipación 2, Lom, Universidad Arcis, Santiago.

Vezzetti, H. (2002). Pasado y presente. Guerra, dictadura y sociedad en la Argentina. Buenos Aires: Editorial Siglo XXI.

Vinyes, R. (2009). "Memorias, relatos, museos". Conferencia presentada en "Experiencias nacionales e internacionales de Museos de la Memoria". Flacso, Santiago de Chile, 5 y 6 de noviembre.

White, H. (2003). El texto histórico como artefacto literario. Barcelona: Paidós. 